REVIEW ARTICLE

\title{
A review on the phytochemical properties of five selected genera of orchids
}

\author{
Lalrosangpuii $^{* 1}$ and Lalrokimi ${ }^{2}$ \\ ${ }^{1}$ Department of Life Sciences, Pachhunga University College, Aizawl 796001, India \\ ${ }^{2}$ Department of Biotechnology, Mizoram University, Aizawl 796004, India
}

\begin{abstract}
Orchidaceae family includes some of the most important ornamental plants with medicinal purposes. It is one of the largest groups among the Angiosperms. Even though there are several studies on the medicinal purposes of orchidaceae, lesser is known about the phytochemical compound present in the different parts of the plant. Therefore, in this present review paper five genus from Orchidaceae family has been selected to highlight the important phytochemical compounds present in the orchid plant. The commonly found phytochemicals are alkaloid, flavanoid, phenol, terpenoid, steroid and saponin.
\end{abstract}

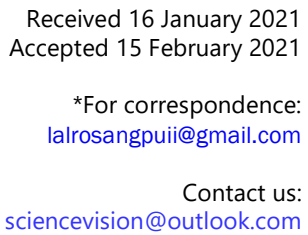

Keywords: Orchid, medicinal plant, ornamental plant, genus, phytocompound.

\section{Introduction}

Orchids comprises the largest and the most diverse group among the flowering plants. ${ }^{1}$ Orchids are generally cultivated for ornamental purposes, but it also happens to have enormous economic importance. The origin of orchids on the earth could be traced back to 120 million years. But the earliest written record was seen on $4^{\text {th }}$ millennium B.C. only. In China, orchids have been used as a source of herbal remedies as early as 2800 B.C. ${ }^{2,3}$ Whereas in India, some orchids have been used for their curative and aphrodisiac properties since the Vedic period (2000-600 B.C. $)^{4}$ Orchid has been mentioned as 'Vanda' in the Indian Vedic scriptures.

There are various types of orchids and is represented by terrestrial, epiphytic and saprophytic species. The occurrence of orchid is worldwide and exhibited different diversity in shape, color, and size of the flowers. They have an aesthetical and medicinal importance, and are also considered as an ecological indicator. ${ }^{5}$ In Europe and Asia orchids are known for its medicinal purposes since ancient times, ${ }^{6}$ but lesser was known about its therapeutic use in the New World. ${ }^{7}$

Orchids are popularly known for their aesthetic value but less for their medicinal values. There has been a tremendous research reports recently as medicinal plants, however, orchids are not completely explored for its medicinal applications and pharmacological studies. ${ }^{8}$ Among the orchids, the genera Dendrobiun, Coelogyne, Cymbidium, Cypipedium, Eria, Anoectochilus, Calanthe, Bulbophyllum, Dactylorhiza, Habenaria, Nevilia, Pholidota, Galeola, and Gastrodia are mainly considered to have medicinal value. It has been reported that extracts and metabolites from these different plants parts like flowers, stem and leaves 
has beneficial pharmacological activities such as diuretic, anti-rheumatic, anti- inflammatory, anticarcinogenic, hypoglycemic activities, anti-microbial, anti-convulsive, relaxation, neuroprotective and anti - virus activities. ${ }^{8}$ A number of chemical compounds such as alkaloids, bibenzyle derivatives, flavonoids, phenanthrenes and terpenoids have been isolated from orchids worldwide. The most common alkaloids extracted include chysine, drobine, dendronine, grandifolin and crepidine. ${ }^{8}$ Chemical components of orchid isolated from Europe and Asia has shown significant antimicrobial activity against human pathogens. $^{6}$

There has been a significant scientific report on orchids as medicinal plants with an abundant number of papers published on this specific topic. However lesser number of review papers regarding the phytochemical properties on orchids has been published. For this reason we decided to focus more on the presence of different phytochemical compound by selecting five genus.

\section{Features of Orchidaceae}

The plants under the Orchidaceae family comprises of extensively evolved and widely distributed monocotyledons with a large number of terrestrial, saprophytic and epiphytic species. It comprises of nearly 30,000 species in which falls under about 750 genera. ${ }^{9}$ Orchids are of very high aesthetic beauty and therefore account for multi million dollars in cut flower industries in many parts of the world. ${ }^{10,11}$ The original home of orchids is believed to be South-East Asian Tropic (Indo-Malaya Regions), where there is high concentration of genera, species and individuals.

\section{Phytochemicals in Orchids}

Phytochemicals are non-nutritive chemical constituents of plants which occur naturally in it, i.e., the chemicals which are derived from plants are called Phytochemicals. ${ }^{12}$ The major chemical constituents reported from orchid species are alkaloids, terpenoids, flavonoids, tannins, bibenzyl derivatives, phenanthrenes and stilbenoids. Presence of these phytochemicals provides antimicrobial, antitumor, anti-inflammatory, antiviral activities, etc.

Alkaloids are known to have antipyretic activity, ${ }^{13}$ and also have the ability to inhibit the $\mathrm{Na}^{+}-\mathrm{K}^{+}$ ATPase activities in kidneys of rats. ${ }^{14}$ Flavanoids have been found to have antioxidative properties, ${ }^{15}$ Anti platelet aggregation activity, ${ }^{16}$ antitumor, $^{17}$ and antifungal activities. $^{18}$ Terpenoids are involved in sensitization of cells that express multi drug resistance phenotype to the toxicity of anticancer drug doxorubicin ${ }^{19}$ and immunomodulatory activity. ${ }^{20,21}$ Bibenzyl derivatives have anticancer activities, $^{22,23,24}$ anti-aggregation activity, ${ }^{25}$ anti- oxidative and antibacterial activity, ${ }^{26,27}$ antiangiogenic activity, ${ }^{28}$ spasmolytic activity, ${ }^{29}$ antitumor activity. ${ }^{30}$ Phenanthrenes have also been found to exhibit anti-tumor, anti-fungal, antioxidative, anti-aggregation, spasmolytic activity, cytotoxic $^{31}$ and anti-inflammatory activities.

\section{Genus Liparis}

Liparis is a genus that comprises of about 250 members. $^{32}$ Among the orchidaceae family, the genus Liparis is one of the first to be investigated for the presence of alkaloids. Boorsma (1902) was the first person to report the presence of alkaloids in $L$. parviflora. Liparis is not commonly used for medicinal purposes except in China despite the presence of alkaloids in many species. ${ }^{33}$

\section{Liparis regnieri}

Liparis regnieri is an herbaceous plant from orchidaceae family. It is one of the members of the genus Liparis. Its common name is Regnier's Liparis. The whole plant is used for extract preparation. The phytochemical studies on Liparis regnieri includes phenanthrene glycosides namely nudoglycosides $A$ and $\mathrm{B}^{34}$ These phenanthrenes are a great compound for antimicrobial activity. In the same plant Ren et al., 2017 has reported biphenanthrene named liparisbiphenanthrene $A$ and ten new nervogenic acid derivatives namely liparisbenzoate $B$, liparisbenzoate $C$, liparisbenzoate $D$, liparisbenzoate $E$, liparisbenzoate $F$, liparisbenzoate $G$, liparisbenzoate $H$, liparisenoate $A$, liparisenoate $B$, liparisacrylate $A$, and liparisacrylate $B$.

\section{Liparis nervosa}

A small terrestrial herb no taller than $12 \mathrm{~cm}$, stem is fleshy, erect, sheathed by two plicate, ovate to ovate-elliptical, pointed leaves. It is mainly used for detoxicating and hemostatic functions. ${ }^{35}$ Pyrrolizidine-alkaloids which has an antitumor activity has been isolated from Liparis nervosa ${ }^{36}$. Huang et al., $2013^{37}$ has also reported five new nervogenic acid derivatives such as 3,5-bis (3-methyl -2-butenyl)-4-O-[ $\beta$-D-glucopy-ranosyl-(1 $\rightarrow 4)-\beta$-Dglucopyranosyl] ben-zoic acid, 3,5-bis (3-methyl-2butenyl) -4-O- [ $\beta$-D-glucopyranosyl- $(1 \rightarrow 2)-\alpha-L-$ arabinopyranosyl] benzoic acid, 3,5-bis(3-methyl-2butenyl)-4-O-[ $\beta$-D-glucopyranosyl- $(1 \rightarrow 2)-\beta-D-g l u c o-$ pyranosyl] benzamide, 3,5-bis(3-methyl-2-butenyl)-4 -O-[ $\beta$-D-gluco-pyranosyl- $(1 \rightarrow 2)-\alpha$-L-arabinopyranosyl] ben-zamide and 3,5-bis(3-methyl-2-butenyl)-4-

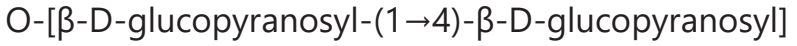
benzamide. In 2016, the ethanolic extract of the whole plant of Liparis nervosa was found to have nervosine VII, nervosine VIII and nervosine IX. These are pyrrolizidine alkaloids and the structures were 
extensively elucidated with spectroscopic examination. $^{38}$ Three new biphnanthrenes was again isolated from the ethanolic extract of Liparis nervosa by bioactivity-guided fractionation. The three new biphenanthrenes includes liparis-phenanthrenes $A_{i}$ liparisphen-anthrenes $B$ and liparisphenanthrenes $C$. These biphenanthrenes are found to have potent cytotoxic activity against stomach (HGC-27) and colon (HT- 29) cancer cell lines. ${ }^{39}$ On a study conducted by Song et al., 2013, the butanol extract was found to have new nervogenic acid glycoside where the structure elucidated by extensive spectroscopic measurements was 3, 5-bis (3-methylbut-2-enyl)-4-O-[ $\beta$-D-xylopyra-nosyl- $(1 \rightarrow 2)-\beta-D-$

glucopyranosyl]-benzoic acid. It was also found to promote ADP-induced platelet aggregation. From the butanol extract itself Adenosine was isolated for the first time in this plant.

\section{Liparis japonica}

Liparis japonica is a perennial hermaphrodite plant. It has the effects of promoting blood circulation and stopping bleeding, ${ }^{40}$ reducing swelling and relieving pain (Institute of Jilin Traditional Chinese Medicine, 1982), and its whole plant is used in folk remedies for tonsillitis and bruises. ${ }^{41}$ From Liparis japonica one new lignan glycoside (7R,8S)-9'-acetyl-dihydro-dehy-

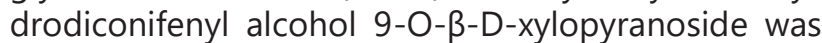
isolated along with six known lignanoids and four known flavonoids were isolated from the Ethyl alcohol extract of Liparis japonica. After elucidating the structures it was proved that the known liganoids are illiciumlignan $D$, illiciumlignan $F$, tetracentronside $\quad B, \quad\left(7 R^{\prime}, \quad 8 S^{\prime}\right)$-dihydrodehydrodiconifenyl alcohol 9'-O- $\beta$-Dxylopyranoside, (- )-dehydrodiconiferyl alcohol, (- )dihydrodehy- drodiconiferyl alcohol, quercetin, quercetin-3-O- $\alpha$-D-arabinopyranoside, kaempferol3-O- $\alpha-D$-arabinopyranoside and dihydroapigenin. ${ }^{42}$

\section{Genus Vanda}

The genus Vanda is famous for ornamental purposes due to its beautiful flower that it produced. Vanda belonging to Orchidaceae family consists of about 73 species. It is widely distributed in Southeast Asia and is most popular especially in India ${ }^{43}$. The name Vanda comes from Sanskrit language ${ }^{44}$ and the different species of Vanda genus are commonly used in the treatment of rheumatic pain, ear infection and nervous system disorders which was mentioned in one of the ancient Sanskrit literature named 'Sushrutasamhita', where it was given under the name of "Rasna" in Ayurvedic formulations. 7,45 Vanda species are being used in the folk medicine in various part of the Asia, mainly in India, Nepal, China and Bangladesh. ${ }^{46-48}$

\section{Vanda coerulea}

Vanda coerulea is a monopodial orchid, an epiphytic plant commonly found in the northeastern region of India (Meghalaya, Mizoram, Assam and Manipur) and northern parts of Thailand and Burma. Vanda coerulea is primarily used for ornamental as well as horticultural purposes. Apart from its ornamental values, it is also an important ethno botanical plant and used to prepare several traditional medicines, which is due to the presence of several biochemical compounds such as flavidin, coelonin, imbricatin, gigantol, methoxycoelonin, phytosterol ${ }^{49}$. The common name for Vanda coerulea is "Blue Vanda of Asia" and "Autumn lady's tresses". Due to habitat destruction, overexploitation, extensive collection, deforestation there is a huge decline of this species from its natural habitat and it has been enlisted as threatened species and included in Appendix II of the Convention on International Trade in Endangered Species of Wild Fauna and Flora (CITES). ${ }^{50}$ The presence of different phytochemical compound such as alkaloid, carbohydrates, glycoside, phenol, $\alpha$-amino acid, saponin, tannin, flavonoid, steroid, terpenoid, reducing sugar and starch was reported from studying the whole plant extract of Vanda coerulea. ${ }^{51}$ From examining the ethanolic extracts of Vanda coerulea, several phytochemical constituents namely methoxycoelonin, imbricatin and gigantol was identified. These constituents were also found to have anti-aging properties. ${ }^{52}$ Flavidin and imbricatin were extracted and identified from stems of Vanda coerulea. Additionally, two phenanthrene derivatives, coelonin and methoxycoelonin were also reported from the stems of Vanda coerulea. ${ }^{49}$

\section{Vanda tessellate}

Vanda tessellate is an epiphytic perennial plant, and a horticultural and medicinally important orchid. The common name of Vanda tessellate is grey orchid. It is commonly found in India and IndoChina. In the study conducted using different solvents extraction of the leaves and flowers, phytochemicals such as alkaloids, anthocyanins, anthraquinones, cardiac glycosides, coumarins, flavonoids, flavones, glycosides, tannins, terpenoids, saponins, phenols and phalobatannin were reported to be present on both the leaves and flowers of Vanda tessellate. ${ }^{53}$ Petroleum ether extract of leaves of Vanda tessellate showed potent 1, 1-diphenyl-2picrylhydrazyl (DPPH) and nitric oxide (NO) radicals scavenging activities. ${ }^{54}$ In another study conducted by Gupta (2016), a new compound named 3-ethoxy10,17 dimethyltetradecahydro-1H-cyclopenta[a] phenanthren-17(2H)-one, was isolated from Vanda tessellate which showed potent antibacterial activity against B. subtilis, E. coli and Proteus mirabilis. Another phenanthropyran derivative such as, 
tessallatin from the whole plant of Vanda tessalatewas identified. ${ }^{55}$ Additionally, from the whole plant of Vanda tessellate a phenanthropyrone derivative which was named as oxo-tessallatin was extracted and identified. ${ }^{56}$

\section{Vanda teres}

Simmler et al., $2011^{57}$ has isolated and identified three new derivatives of glucopyranosyloxybenzyleucomate, i.e., vandateroside I-III along with eucomic acid from Vanda teres stem for their anti-aging effects in immortalized keratinocyte cellline of human origin ( $\mathrm{HaCaT})$. Similarly, Vandaterosides which are eucomate derivatives were isolated from different solvent fraction prepared from Vanda teres extract. ${ }^{58}$ In another study conducted using three solvents namely Petroleum ether, ethanol and methanol of plant extraction, it was found that in petroleum ether extract alkaloid, saponin and tannin were present, and in ethanolic extract alkaloid, steroid, saponin and tannin were found to be present whereas in the methanolic extract alkaloid, reducing sugars, flavonoid, steroid, saponin and tannin were present. $^{59}$

\section{Genus Bulbophyllum}

The genus Bulbophyllum is one of the largest genera of the Orchidaceae family consisting of about 1000 species. Bulbophyllum are mostly found in Asia, America and Africa. There are 100 species in India. ${ }^{60}$ The generic name Bulbophyllum is derived from the Greek words bulbo (bulb) and phyllon (leaf). The plant maybe perennial, epiphytic or lithophytic herbs, rhizome may or not may not be present. Pseudobulbs is present on the rhizome and could be distant or clustered.

\section{Bulbophyllum neilgherrense}

Bulbophyllum neilgherrense is an epiphytic monocot of Orchidaceae family. It is abundantly contained in the Western Ghats region. ${ }^{61}$ It is endemic to South India mainly in the forest of Kerala, Karnataka and Tamil Nadu. The distinct characteristic of the plant is the presence of green, angled pseudobulb, which is a solid bulbous enlargement of the stem to preserve water and nutrients. Pseudobulbs in this orchid are $4 \mathrm{~cm}$ long and $2 \mathrm{~cm}$ across, smooth, green and four angled. Different phytochemical compounds such as alkaloids, tannins, phenols, flavonoids, steroids, saponin glycosides and reducing sugar were found in pseudobulb extract, additionally, a flavonoid known as Chrysin which was detected in the methanolic extract of the pseudobulb was found to have anti hyperlipidemic and anti-inflammatory activity ${ }^{62}$. The same author has also found the presence of alkaloids, tannins and phenols in the methanolic extract of the leaf, stem and root of $B$. neilgherrense. Simultaneously the water extract of leaf has also showed reducing sugars and saponin glycoside. $^{62}$

\section{Bulbophyllum odoratissimum}

Bulbophyllum odoratissimum is an epiphyte belonging to Orchidaceae family. It is commonly found in Asian countries such as China, India, Nepal, Burma, Bhutan, Thailand, Laos and Vietnam, it is widely used as folk medicine to treat tuberculosis, chronic inflammation and fracture. ${ }^{63,64}$ Lin et al., ${ }^{74}$ have discovered three new Dihydrostilbenes from the whole plant of $B$. odoratissimum which was having a significant cytotoxicity toward human cancer cell lines. A new compound known as Bulbophyllinoside was discovered in the whole plant investigation of $B$. odoratissimum. ${ }^{39}$ A new phenanthraquinone named bulbophyllanthrone was isolated from $B$. odoratissimum along with known flavonoids chrysin and pinobanksin. ${ }^{65}$ From the investigation of the whole plant of $B$. odoratissimum the following compounds were isolated moscatin, coelonin, densiflorol B, gigantol, batatasin III, tristin and two simple aromatic compounds namely vanillic acid and syringaldehyde. ${ }^{36}$

\section{Bulbophyllum vaginatum}

Bulbophyllum vaginatum is commonly known as The Vagina. It is commonly found in Malaysia, Thailand, Java and Borneo. Bulbophyllum vaginatum collected from Singapore was found to have biphenanthrene and phenanthrene [4, 3-b] furan derivative. These compounds were found from the whole plant study of Bulbophyllum vaginatum. ${ }^{66}$ Two new phenanthrenes (4,9-dimethoxyphen-anthrene2,5-diol and 4,6-dimethoxyphen-anthrene-2,3,7triol) and two new 9,10-dihydrophenanthrenes (4methoxy-9,10-dihydrophenanthrene-2,3,7-triol and 4,6-dimethoxy-9,10-dihydrophenanthrene-2,3,7triol. $^{67}$ Later continuing the studies two new phenanthrenes (4-methoxyphenanthrene-2,3,7-triol and 4-methoxyphenanthrene-2,3,6,7-tetrol) and two new 9,10- dihydrophenanthrenes (5-methoxy-9,10dihydrophenanthrene-2,3,7-triol and 4-methoxy9,10-dihydrophenan-threne-2,3,6,7-tetrol) were isolated from the dichloromethane extract of Bulbophyllum vaginatum. ${ }^{67}$

\section{Genus Acampe}

Acampe is a genus of monopodial, epiphytic vandaceous species of orchids, distributed from tropical Asia from India, China, Malaysia, Philippines as well as Africa and Madagascar. They have thick, leathery, distichous leaves. They are large in size but 
have rather small flowers, and this is the reason they are rarely cultivated. Eight different species are recognized under this genus.

\section{Acampe praemorsa (Roxb)}

Acampe praemorsa is an epiphytic wild orchid. It is a robust plant with stout stem, covered by sheathing bases of leaves, with persisting old inflorescence axis and long stout aerial roots among the leaves. The flowers are dense, not wide openings, yellowish in colour and have a mild sweet smell. The phytochemical study of Acampe praemorsa (Roxb) showed the presence of alkaloid, flavanoid, phenol, terpenoid and steroid constituents. The aqueous extract showed the presence of saponin, phenol, terpenoid, tannin and glycoside. The ethanolic extract further revealed saponin, phenol, terpenoid, tannin and steroid. However, silver nitrate extract revealed the presence of terpenoid, tannin and steroid constituents. ${ }^{68}$ Cyanogenic glycosides and flavonoids have also been reported from the phytochemical studies of Acampe praemorsa. ${ }^{69}$ Praemorsin, a newly recorded phenanthropyran was isolated from the whole plant of A.praemorsa. ${ }^{70}$ Two compounds, namely flavidin and flavidinin have also been isolated from this orchid. The petroleum ether extract of Acampe praemorsa leaf showed significant activity against $E$. coli and the methanolic extract showed good zone of inhibition against the bacterium, Klebsiella pneumonia. ${ }^{71}$ The ethyl acetate extract showed good antibacterial activities against Lactobacillus acidophilus, Klebsiella pneumonia, Escherichia coli and Enterococcus faecalis. ${ }^{71}$ Antifungal activity against Candida albicans is also exhibited by the methanolic and ethyl acetate extracts of Acampe praemorsa. In vitro cytotoxic potential of ethyl acetate extract of Acampe praemorsa is also found to be very significant against the HeLa and MCF-7 cell lines. ${ }^{71}$

\section{Acampe papillosa (Lindl.) Lindl}

Acampe papillosa is an epiphytic orchid native to the Himalayas. This plant produces small, strongly fragrant, long lasting flowers which are present near the axils of the leaf. Akter et $a l^{73}$ screened the plant for phytochemicals and found that the leaf extract of the plant contained a sufficient amount of alkaloids. Secondary metabolites like glycosides, flavonoids, tannins, terpenoids, steroids, quinine and coumarin were also found to be sufficiently present and is therefore considered as a very potent medicinal orchid. Both the water and acetone extracts of Acampe papillosa showed good antibacterial property when tested against the non-resistant (MTCC), Ampicillin resistant and Kanamycin resistant strains of $E$. coli. ${ }^{72}$

\section{Acampe Ochracea (Lindl.) Hochr}

Acampe Ochracea is an epiphytic orchid native to India, Bangladesh, Sri Lanka, Cambodia, Laos, Myanmar, Thailand, Malaysia and Vietnam. The water and acetone extracts of $A$. ochraceae showed good antibacterial activity against non-resistant strain, ampicillin resistant strain and kanamycin resistant strains of $E$. coli with the water extract showing maximum zone of inhibition against kanamycin resistant strain cultured in kanamycin suspended LB agar. $^{72}$

\section{Genus Aerides}

This genus is native to the tropics of Asia, India, Nepal, Southern China, Southeast Asia, Philippines and New Guinea. They are monopodial epiphytic plants with waxy flowers which are usually white with purple or pink edges.

\section{Aerides odaratum Lour.}

Phytochemical screening of the leaf extracts of $A$. odaratum was found to contain secondary metabolites like glycosides, flavonoids, tannins, terpenoids, steroids, quinine, coumarin. Lower presence of saponins and anthroquinone was observed. Phlobatannin test indicated its absence in Aerides odaratum. The qualitative test for alkaloids from the leaf extract of $A$. Odaratum showed high presence of alkaloids in Dragendorff's reagent, Hager's reagent, Wagner's reagent and in Tannic acid reagent ${ }^{73}$. The water and acetone extracts of Aerides odaratum showed good antibacterial efficacy against three strains of $E$. coli i.e., the ampicillin resistant variety, the kanamycin resistant variety and the non-resistant varieties. $^{75}$ Jhansi \& Khasim $^{71}$ studied the antibacterial and antifungal activities of A. odaratum in terms of zone of inhibition of their growth. The ethyl acetate extract in comparison with the metanolic extract was found to be more active against Lactobacillus acidophilus with an inhibition zone of $17 \mathrm{~mm}$. It also showed good efficacy against Bacillus megaterium, Escherichiacoli, Enterococcus fecalis and Proteus vulgaris. A. odorata also showed good antifungal activity with an inhibition zone of 14 $\mathrm{mm}$ against Candida albicans. Methanolic extract of Aerides odorata showed a very significant In vitro cytotoxicity against MCF-7 cell lines and was found to suppress more cell proliferation in comparison with the HeLa cell line. ${ }^{71}$

\section{Aerides crispum}

Aeridin, a new natural compound which is a phenanthropyran derivative was isolated from Aerides crispum. Its structure was expounded as 2,7dihydroxy-1,3-dimethoxy-9,10-dihydroxyphenan- 
thropyran. $^{55}$

\section{Conclusion}

The present study deals with the study of five genus from Orchidaceae family and concludes that besides having several beneficiary health effects and pharmaceutical activities, Orchidaceae family has several active phytochemical compounds which are present in different parts of the plant. These compounds indicate their potential use in pharmaceutical development. Although, India is blessed with the presence of a several different species of orchid, some of them are at the verge of extinction. So, this review helps us to gain the importance of conserving the orchid from extinction by mentioning some of the important phytochemical compounds present in various genus of Orchidaceae family. Hopefully in the future we will be able to utilise these phytochemical compounds for the discovery of medicinal drugs.

\section{References}

1. Dressler, R (1981). The Orchids: Natural History and Classification. Harvard University Press.

2. Kimura, K., Migo, H.J. (1936). Shanghai Sci Inst, 3:121-4.

3. Lüning, B. (1974). Alkaloid content of Orchidaceae. In: Withner C L, editor. The Orchids: Scientific Studies. New York: John Wiley and Sons

4. Kaushik, P. (1983). Anatomical and ecological marvels of the Himalayan orchids. New Delhi, India: Today and Tomorrow's Printers and Publishers.

5. Joshi, G., Tewari, L.M., Lohani, N., Upreti, K., Jalal, J.S., Tewari, G. (2009). Diversity of orchids on Uttarakhand and their conservation strategy with special reference to their medicinal importance. Rep. Opin, 1, 47-52.

6. Sut, S., Maggi, F., Dall'Acqua, S. (2017). Bioactive secondary metabolites from orchids (Orchidaceae). Chem. Biodivers, 1-14 e1700172.

7. Hossain, M.M., (2011). Therapeutic orchids: traditional uses and recent advances - an overview. Fitoterapia, 82,102-140.

8. Rosa, M.P.G., (2010) Orchids: A review of uses in traditional medicine, its phytochemistry and pharmacology. Journal of Medicinal Plants Research $4(8)$, 592-638

9. Johnson, M., Janakiraman, N. (2013) Phytochemical and TLC studies on stem and leaves of the orchid Dendrobium panduratum subspecies villosum Gopalan and A. N. Henry. Indian J Nat Prod Res, 4(3), 250-254.
10. Bose, TK., Bhattacharjee, S.K., Das, P., Basak, U.C. (1999). Orchids of India.

11. Vij. S.P., Sood, A., Sharma, M. (1986) In vitro leaf segment culture of Vanda tastacea. Current science (Bangalore). 55, 1100-1101.

12. Singh, K., Nayak, B. (2003) Phytochemical determination and antibacterial activity of Trichosanthesdioica Roxb (Patal), Cucurbita Maxima (pumpkin) and Abelmoschus esculentus Moench (Okra) plant seeds. Journal of pharmacognosy, 1-6.

13. Chen, K.K., Chen, A.L. (1935). The alkaloid of Chin -Shih-Hu. J. Biol. Chem, 653-658.Akter, M., Huda, M.K, Hoque, M.M. (2018). Investigation of secondary metabolites of nine medicinally important orchids of Bangaladesh. Journal of Pharmacognosy and Phytochemistry, 7(5), 602-606.

14. Li, M.F., Hirata, Y., Xu, G.J., Niwa, M., Wu, H.M. (1991). Studies on the chemical constituents of Dendrobium loddigesii rolfe.Yao Xue Xue Bao, 26, 307 -310 .

15. Fan, C., Wang, W., Wang, Y., Qin, G., Zhao, W. (2001).Chemical constituents from Dendrobium densiflorum. Phytochemistry, 57, 1255-1258.

16. Markham, K.R., Ternai, B., Stanley, R., Geiger, H., Mabry, T.J. (1978). Carbon- 13 NMR studies of flavonosides-III: Naturally occuring flavonoid glycosides and their alylated derivatives. Tetrahedron, 34, 1389-1397.

17. Peng, J., Xu, Q., Xu, Y., Qi, Y., Han, X., Xu, L. (2007). A new anticancer dihydroflavanoid from the root of Spiranthes australis (R. Brown) Lindl. Nat. Prod. Res, 21,641-645.

18. Shimura, H., Matsuura, M., Takada, N., Koda, Y. (2007). An antifungal compound involved in symbiotic germination of Cypripedium macranthos var. rebunense (Orchidaceae). Phytochemistry, 68, 1442-1447.

19. Na, G.X., Wang, T.S., Yin, L., Pan, Y., Guo, Y.L., LeBlanc, G.A., Reinecke, M.G., Watson, W.H., Krawiec, M. (1998). Two pimarane diterpenoids from Ephemerantha lonchophylla and their evaluation as modulators of the multidrug resistance phenotype. J. Nat. Prod, 61,112-115.

20. Zhao, C., Liu, Q., Halaweish, F., Shao, B., Ye, Y., Zhao, W. (2003). Copacamphane, picrotoxane, and alloaromadendrane sesquiterpene glycosides and phenolic glycosides from Dendrobium moniliforme. J. Nat Prod, 66 (8), 1140-3

21. Ye, Q., Qin, G., Zhao, W. (2002). Immunomodulatory sesquiterpene glycosides from Dendrobium nobile. Phytochemistry, 61,885-890. 
22. Miyazawa, M., Shimamura, H., Nakamura, S., Sugiura, W., Kosaka, H., Kameoka, H. (1999). Moscatilin from Dendrobium nobile, a naturally occurring bibenzyl compound with potential antimutagenic activity. J. Agric. Food Chem, 47, 2163-2167.

23. Chen, C.C., Wu, L.G., Ko, F.N., Teng, C.M. (1994). Antiplatelet aggregation principles of Dendrobium loddigesii. J. Nat. Prod, 57.1271-1274.

24. Ho, C.K., Chen, C.C. (2003). Moscatilin from the orchid Dendrobrium loddigesii is a potential anticancer agent. Cancer Investigation, 21,729-736.

25. Chen, C.C., Huang, Y.L., Teng, C.M. (2000). Antiplatelet aggregation principles from Ephemerantha lonchophylla. Planta Medica, 66, 372374.

26. Venkateswarlu, S., Raju, M.S., Subbaraju, G.V. (2002). Synthesis and biological activity of isoamoenylin, a metabolite of Dendrobium amoenum. BiosciBiotechnolBiochem, 66, 2236-2238.

27. Zhang, X., Xu, J.K., Wang, J., Wang, N.L., Kurihara, H., Kitanaka, S., Yao, X.S. (2007). Bioactive bibenzyl derivatives and fluorenones from Dendrobium nobile. J. Nat. Prod, 70, 24-28.

28. Gong, Y.Q., Fan, Y., Wu, D.Z., Yang, H., Hu, Z.B., Wang, Z.T. (2004). In vivo and in vitro valuation of erianin, a novel antiangiogenic agent. Eur. J. Cancer, 40, 1554-1565.

29. Hernández-Romero, Y., Rojas, J.I., Castillo, R., Rojas, A., Mata, R. (2004). Spasmolytic effects, mode of action, and structure activity relationships of stilbenoids from Nidema boothii. J. Nat. Prod, 67, 160-167.

30. Wu, B., He, S., Pan, Y.J. (2006). New dihydrodibenzoxepins from Bulbophyllum kwangtungense. Planta Medica, 72, 1244-1247.

31. Xue, Z., Li, S., Wang, S., Wang, Y., Yang, Y., Shi, J., $\mathrm{He}$, L. (2006). Mono-, Bi-, and triphenanthrenes from the tubers of Cremastra appendiculata. J. Nat. Prod, 69,907-913.

32. Seidenfaden, G. \& Wood, J.J. (1992) The Orchids of Peninsular Malaysia and Singapore. Fredensborg: Olsen, p. 779.

33. Wu, Z. Y. (1990). XinHuaBenCaoGang Yao (Vol. 3). Shanghai: Shanghai Press of Science and Technology, p. 574.

34. Ren, J., Qian, X.P., Guo, Y.G., Li, T., Yan, S.K., Jin, H.Z., Zhang, W.D. (2016). Two new phenanthrene glycosides from Liparis regnieri Finet. and their antibacterial activities. Phytochem Lett, 18, 64-67.

35. Hua, Y.X., Liu, S.F., Yang, Z.Q. (1999). The Chinese
Herbal, vol. 12. Shanghai Science and Technology Publishing House Press, Shanghai, p. 997.

36. Chen, L., Huang, S., Li, C.Y., Gao, F., Zhou, X.L. (2018). Pyrrolizidine alkaloids from Liparisnervosa with antitumor activity by modulation of autophagy and apoptosis. Phytochemistry, 153, 147 -155 .

37. Huang, S., Zhou, X., Wang, C., Wang, H., Wang, Y., Shan, L., \& Weng, J. (2013). New nervogenic acid derivatives from Liparis nervosa. Planta Medica, 79(03/04), 281-287.

38. Huang, S., Zhong, D.X., Shan, L.H., Zheng, Y.Z., Zhang, Z.K., Bu, Y.H., Ma, H.W., Zhou, X.L. (2016). Three new pyrrolizidine alkaloids derivatives from Liparis nervosa. Chin. Chem. Lett, $27,757-760$

39. Liu, L., Yin, Q.M., Zhang, X.W., Wang, W., Dong, X.Y., Yan, X., Hu, R. (2016). Bioactivity-guided isolation of biphenanthrenes from Liparis nervosa. Fitoterapia, 115, 15-18.

40. Gao, S. (2010). Liaoning J. Tradit. Chin. Med. Liaoning Science and Technology Press, Shenyang, p. 1203.

41. Fang, Z.X., Zhao, H., Zhao, J.H. (2006). Annals of Tujia Medicine. China Medical Science and Technology Press, Beijing.

42. Liang, W., Sun, L.-Q., Qian, F., Tian, X.-H. (2020). Chemical constituents from the whole plant of Liparis japonica. Biochemical Systematics and Ecology, 92, 104126.

43. Gardiner, L.M., Kocyan, A., Motes, M., Roberts, D.L., Emerson, B.C. (2013). Molecular phylogenetics of Vanda and related genera (Orchidaceae). Bot. J. Linn. Soc, 173, 549-572.

44. Garay, L.A. (1974). On the Systematics of the Monopodial Orchids II. Botanical Museum Leaflets, Harvard University, pp. 369-375.

45. Khasim, S.M., Rao, P.M. (1999). Medicinal importance of orchids. Botanica, 49, 86-91.

46. Kumar, C.S., Kumar, P.S. (2005). An orchid digest of Manipur, Northeastern India. Rheedea, 15, 1-70.

47. Dash, P.K., Sahoo, S., Bal, S. (2008). Ethnobotanical studies on orchids of Niyamgiri hill ranges, Orissa, India. Ethnobot. Leafl, 12,70-78.

48. Hossain, M.M. (2009). Traditional therapeutic uses of some indigenous orchids of Bangladesh. Med. Arom. Plant Sci. Biotech, 42, 101-106.

49. Simmler, C., Antheaume, C., Lobstein, A. (2010). Antioxidant biomarkers from Vanda coerulea stems reduce irradiated HaCaT PGE-2 production as a result of COX-2 inhibition. PloS One, 5 (10), 
e13713.

50. Hrahsel, L., Thangjam, R. (2015). Asymbiotic in vitro seed germination and regeneration of Vanda coerulea Giff. Ex. Lindl., an endangered orchid from Northeast India. J Plant Sci Res, 2, 133-137.

51. Thant, K.M., Zan, B., Yu,H. (2019). Study on phytochemical constituents and antimicrobial activities of some Myanmar medicinal orchids. $2^{\text {nd }}$ Myanmar Korea Conference Research Journal.

52. Bonté, F., Simmler, C., Lobstein, A., Pellicier, F., Cauchard, J.H. (2011). May. Action d'un extrait de Vanda coerulea sur la sénescence de fibroblastescutanés. In Annales Pharmaceutiques Françaises. Elsevier Masson, 69, 177-181.

53. Biswas K., Sinha S.N. (2020) Evaluation of Phytoconstituents and Antibacterial Activity of Vanda tessellata Using In Vitro Model. In: Khasim S., Hegde S., González-Arnao M. Thammasiri K. (eds) Orchid Biology: Recent Trends $\mathcal{E}$ Challenges. Springer, Singapore.

54. Vijaykumar, K. (2013). In vitro anti-oxidant activity of pet-ether extract of Vanda tessellata Roxb. Int. Ayur. Med. J, 1, 1-4.

55. Anuradha, V., Rao, N.S.P. (1998a). Tessallatin a phenanthropyran from Vanda tessalata. Phytochemistry, 48, 183-184.

56. Anuradha, V., Rao, M.V.B., Aswar, A.S. (2008). Oxo-tessallatin, a novel phenanthrapyran isolated from from Vanda tessalata. Orient. J. Chem, 24, 11191122.

57. Simmler, C., Antheaume, C., André, P., Bonté, F., Lobstein, A. (2011). Glucosyloxybenzyl eucomate derivatives from Vanda teres stimulate HaCaT cytochrome c oxidase. J. Nat. Prod, 74,949-955.

58. Cakova, V., Urbain, A., Le Quéméner, C., Audo, G., Bonté, F., \& Lobstein, A. (2015). Purification of vandaterosides from Vanda teres (Orchidaceae) by stepwise gradient centrifugal partition chromatography. Journal of Separation Science, 38 (17), 3006-3013.

59. Mazumder, P.B., Sharma, G.D., Choudhury, M.D., Nath, D., Talukdar, A.D., Mazumder, B. (2010). In vitro propagationnd phytochemical screening of Papilionanthe teres (Roxb.) Schltr. Assam University Journal of science and Technology, Biological and Environmental Science. 5, 37-42.

60. Chowdhery, H J, (1998), Orchid Flora of Arunachal Pradesh. Bishen Singh Mahendra Pal Singh.

61. Rajendran, A., Rao, N R., Kumar, KR., Henry, AN. (1997) Some medicinal orchids of Southern India. Ancient Science of Life.
62. Kumari, P., George, SI., Rajmohan, K. (2013) Influence of plant growth regulators on in vitro clonal propagation of dendrobium sonia 'earsakul'. Journal of Bio Innovation.

63. Qu, X. Y., Qin, S. Y., Yang, D. Q., Li, Q. S., \& Peng, F. S. (2006). Study on resource and varieties of Guoshangye. China Journal of Chinese Materia Medica, 31(2), 110-114.

64. Wu, Z. Y. (1990). XinHuaBenCaoGang Yao (Vol. 3). Shanghai: Shanghai Press of Science and Technology, p. 574.

65. Majumber, P.L. \& Sen, R.C. (1991) Pendulin, a polyoxygenated phenanthrene derivative from the orchid Cymbidium pendulum. Phytochemistry. 30, 7, 2432-2434.

66. Leong, Y.-W., Harrison, L.J. (2004-09). A biphenanthrene and a phenanthro[4,3-b]furan from the orchid Bulbophyllum vaginatum. Journal of Natural Products 67 (9), 1601-1603.

67. Leong, Y.W., Harrison, L.J., Powell, A.D. (1999) Phenanthrene and of ther aromatic constituents of Bulbophyllum vaginantum. Phytochemistry.

68. Suji, R.M., Willians, C. (2016). Micropropagation, phytochemical studies and antioxidant potential of a wild epiphyte orchid, Acampe praemorsa (Roxb) of Kanyakumari district, India. European Journal of Pharmaceutical and Medical research, 3.5, 572-476.

69. Maridas. M., Hussain, M.I.Z., Raju, G. (2008). Phytochemical survey of orchids in the Tirunelveli Hills of South India. Ethnobotanical leaflets, 12, 70512.

70. Anuradha, V., Rao, P. (1994). Praemorsin, a new phenanthropyran from Acampae praemorsa. Phytochemistry, 37(3), 909-910.

71. Jhansi, K., Khasim, S.M. (2018). Antimicrobial and in vitro cytotoxic studies of Acampe praemorsa and Aeridis odarata of Orchidaceae. Annals of Plant Sciences, 7(2), 2008

72. Chowdhury, A., Paul, P., Nath, D., Batacherjee, MK., (2013). Anti microbial efficacy of orchids extracts as potential inhibitors of antibiotic resistant strains of E Coli. Asian Journal of Pharmaceutical and Clinical Research 6(3) 108-111.

73. Akter, M., Huda, KM., Hoque, MM., (2018) Investigation of secondary metabolites of nine medicinally important orchids of Bangladesh. Journal of Pharmacognosy and Phytochemistry 2018; 7 (5): 602-606.

74. Lin YL, Chen WP, Macabalang AD (2005). Dihydrophenanthrenes from Bletilla formosana. Chem. Pharm. Bull. 53: 1111-1113. 
75. Paul, P., Chowdhury, A., Nath, D., Bhattacharjee, M.K. (2013). Antimicrobial efficacy of orchid extracts as potential inhibitors of antibiotic resistant strains of Escherichia coli. Asian Journal of Pharmaceutical and Clinical Research, 6, 3 . 